\title{
Establishment of Relational Model of Congenital Heart Disease Markers and GO Functional Analysis of the Association between Its Serum Markers and Susceptibility Genes
}

\author{
Min Liu, ${ }^{1,2}$ Luosha Zhao, ${ }^{1}$ and Jiaying Yuan $^{3}$ \\ ${ }^{1}$ Department of Cardiovascular Medicine, The First Affiliated Hospital of Zhengzhou University, \\ No. 1 East Jianshe Road, Zhengzhou 450052, China \\ ${ }^{2}$ Department of Cardiovascular Medicine, Zhengzhou Central Hospital, Zhengzhou University, \\ No. 195 Tongbai Road, Zhengzhou 450007, China \\ ${ }^{3}$ Department of Ultrasound Diagnosis, Directly under Hospital of Henan Military Region, \\ No. 18 Jinshui Road, Zhengzhou 450000, China \\ Correspondence should be addressed to Luosha Zhao; zhaols12@163.com
}

Received 3 August 2015; Revised 24 September 2015; Accepted 1 October 2015

Academic Editor: Krishna Agarwal

Copyright (c) 2016 Min Liu et al. This is an open access article distributed under the Creative Commons Attribution License, which permits unrestricted use, distribution, and reproduction in any medium, provided the original work is properly cited.

\begin{abstract}
Purpose. The purpose of present study was to construct the best screening model of congenital heart disease serum markers and to provide reference for further prevention and treatment of the disease. Methods. Documents from 2006 to 2014 were collected and meta-analysis was used for screening susceptibility genes and serum markers closely related to the diagnosis of congenital heart disease. Data of serum markers were extracted from 80 congenital heart disease patients and 80 healthy controls, respectively, and then logistic regression analysis and support vector machine were utilized to establish prediction models of serum markers and Gene Ontology (GO) functional annotation. Results. Results showed that NKX2.5, GATA4, and FOG2 were susceptibility genes of congenital heart disease. CRP, BNP, and cTnI were risk factors of congenital heart disease $(p<0.05)$; cTnI, hs-CRP, BNP, and $\mathrm{Lp}(\mathrm{a})$ were significantly close to congenital heart disease $(p<0.01)$. ROC curve indicated that the accuracy rate of $\mathrm{Lp}(\mathrm{a}) \mathrm{and} \mathrm{cTnI}$, $\mathrm{Lp}$ (a) and BNP, and BNP and cTnI joint prediction was $93.4 \%, 87.1 \%$, and $97.2 \%$, respectively. But the detection accuracy rate of the markers' relational model established by support vector machine was only $85 \%$. GO analysis suggested that NKX2.5, GATA4, and FOG2 were functionally related to Lp(a) and BNP. Conclusions. The combined markers model of BNP and cTnI had the highest accuracy rate, providing a theoretical basis for the diagnosis of congenital heart disease.
\end{abstract}

\section{Introduction}

Congenital heart disease (CHD) indicates the presence of abnormality in heart and vascular structure and function at birth, the pathogenesis of which is complex. It is the interaction results of multiple factors like heredity and environment. The known risk factors include mental stimulation during pregnancy [1], harmful substances exposure [2], smoking and drinking [3], viral infections at early stage of pregnancy [4], diabetes mellitus [5], history of unhealthy pregnancy [6], and too high maternal age [7]. Its clinical consequences are extremely serious. It is the important cause of miscarriage, stillbirth, neonatal death, and children, adolescents, and adults with disabilities. The incidence of fetal CHD reaches as much as $6 \%$ to $10 \%$ [8] and continues to show a significant upward trend in China [9].

Currently, CHD is still cured by surgery. Many scholars believe that a number of indicators such as the level of serum C-reactive protein (CRP), brain natriuretic peptide (BNP), cardiac troponin I (cTnI), and Lipoprotein(a) $(\mathrm{Lp}(\mathrm{a}))$ can better reflect the functional status of the heart in patients with CHD and have good potential in clinical analysis. These proteins may serve as indicators in prognosis evaluation.

Since the United States has announced precision medicine plan, countries around the world have increased the support for precision medicine. With the enrichment and 
improvement of clinical big data and biological networks, it has become a general trend to complete interdisciplinary collaboration in disease prediction, diagnosis, and etiology analysis. In daily life, clinicians commonly use Logistic regression analysis to analyze the prognostic factors of the disease and estimate the probability of occurrence of variables [10]. Support vector machine (SVM) is a new machine learning method based on statistical theory. SVM is good at coping with linearly nonseparable sample data, which is achieved mainly through the slack variables (which are also called punishment variables) and kernel technology. It provides a unified framework in solving learning problems of finite samples [11].

Increasing studies show that the pathogenesis of congenital heart disease is related to certain transcription factors, while the relationship between the susceptibility genes and serological markers of congenital heart disease is not yet reported. With the rapid application of bioinformatics, Gene Ontology (GO) has become important tool and method in the field of bioinformatics. In terms of gene function annotation, GO plays a huge role. It can analyze the location of gene or protein in the cell, molecular functions, and biological processes involved; thus it simplifies the annotation of genes and their products as standardized vocabularies.

In this study, data of the susceptibility genes and clinical serology risk factors literatures of $\mathrm{CHD}$ were performed Meta-analysis to systematically evaluate them. By detecting levels of serum markers in patients with CHD, Logistic regression analysis, receiver operating characteristic (ROC) curve, and SVM approaches were used to evaluate the value of each serum marker in clinical diagnosis of CHD. The detection model of serum markers of this disease was then established. The functional relationship between susceptibility genes and serum markers was established by GO analysis. As a result, this study provides a theoretical basis for clinical practice and personalized treatment of cardiovascular disease.

\section{Materials and Methods}

\subsection{Meta-Analysis}

2.1.1. Subjects. Clinical research documents on susceptibility genes and serological markers of CHD published in China and foreign countries from January 2006 to October 2014 were selected.

2.1.2. Document Retrieval. Google Scholar was a major source of Chinese documents; PubMed, EMBASE, MEDLINE, and MD consult were main sources of English documents and the Chinese or English key words were "congenital heart disease", "gene", and "mutation" as well as "congenital heart disease", "serum markers", and "diagnosis". The years of publication were from January 1, 2000, to October 31, 2014.

2.2. Statistical Analysis. RevMan5.1 was used for metaanalysis of the included literature. $p \geq 0.05$ showed that the merge statistics of multiple studies had no statistical significance; $p<0.05$ indicated that the combined statistics were statistically significant.

\subsection{Establishing Relational Model of CHD Markers Group}

2.3.1. Research Data. In this study, $80 \mathrm{CHD}$ patients (33 with atrial septal defect, 36 with ventricular septal defect, 3 with patent ductus arteriosus, and 8 with tetralogy of Fallot) received treatment in the Department of Cardiac Surgery at our hospital from December 2009 to September 2014 (54 males and 26 females, aged from 7 days to 59 years) and 80 healthy outpatients as determined by a physical examination given at the hospital (38 males and 42 females, aged 3.6 months to 51 years) were selected as the subjects. Patients in case group were confirmed by echocardiography and (or) surgery, and the following cases were excluded: (1) renal insufficiency, chronic liver disease, and acute and chronic infectious diseases; (2) systemic lupus erythematosus, rheumatoid, and other immune system diseases; and (3) infectious endocarditis, rheumatic heart disease, cardiac tumors, myocarditis, and other types of heart disease. Healthy control group denied a family history of CHD. They were confirmed to have no cardiac dysfunction and organic diseases by physical examination and echocardiography. Infection, trauma, autoimmune diseases, cancer, and so on were also excluded.

$10 \mathrm{~mL}$ of venous blood was collected from all study subjects in the morning after $12 \mathrm{~h}$ overnight fasting and put into the EDTA anticoagulant tube. Samples were centrifuged within $2 \mathrm{~h}$ at $3000 \mathrm{r} / \mathrm{min}$ for $10 \mathrm{~min}$, and then the supernatants were collected.

2.3.2. Sample Testing. Serum BNP level was detected using enzyme-linked immunosorbent assay (ELISA). Serum hsCRP was examined using immune rate nephelometry. Immunofluorescence method was used to determine serum cTnI level. ELISA double-antibody sandwich assay was adopted to test serum Lp(a) level. Detection methods were carried out in strict accordance with the kit instructions. Each sample received parallel testing twice and the average value was regarded as final test results.

\subsubsection{Establishing Relational Model of CHD Markers Group Based on Logistic Regression Analysis. Serum markers BNP, hs-CRP, cTnI, and Lp(a) levels of CHD patients and healthy control group undergone Logistic regression analysis with the new variables of Logistic regression model as test variables and the pathological diagnosis results as state variables; the ROC curve was drawn. According to the value of the area under the curve (AUC) of ROC and diagnostic accuracy, its application value in early diagnosis of CHD was evaluated.}

\subsubsection{Establishing Relational Model of CHD Markers Group} Based on SVM. Data of the $80 \mathrm{CHD}$ patients were treated with normalization processing. The establishment, training, and validation of SVM model were achieved through MATLAB programming. 
2.3.5. Statistical Analysis. The data obtained undergone significance of difference analysis using statistical software SPSS19.0 and the data were expressed by the following: mean \pm standard deviation. $p<0.05$ indicated that the difference was statistically significant.

\subsection{Bioinformatics Functional Analysis of Serum Markers Lp(a) and BNP and Susceptibility Genes of CHD}

2.4.1. GO Retrieval. Congenital heart disease-related susceptibility genes NKX2.5, GATA4, and FOG2 and serological markers hs-CRP, Lp(a), BNP, and cTnI undergone GO functional annotation using AmiGO platform.

2.4.2. RT-PCR. RNA kit from TAKARA (Takara Bio Inc., Shiga, Japan) was used to extract serum RNA, and Thermo Scientific RevertAid First Strand cDNA Synthesis Kit was used for reverse transcription experiments. With the synthesized cDNA template and GAPDH as template, we performed fluorescence quantitative PCR reactions. Fluorescent dye SYBR and quantitative real-time PCR instrument CFX96 were applied in this experiment. Primers are shown in Table 1 (primers were synthesized by Shanghai Sangon Biotech Co., Ltd., Shanghai, China). $20 \mu \mathrm{L}$ system of PCR reaction was as follows: $10 \mu \mathrm{LSYBG} \mathrm{Mix}+8 \mu \mathrm{L} \mathrm{H}_{2} \mathrm{O}+0.5 \mu \mathrm{L}$ upstream primer $+0.5 \mu \mathrm{L}$ downstream primer $+1 \mu \mathrm{L}$ cDNA; reaction conditions were as follows: denaturation at $95^{\circ} \mathrm{C}$ for $30 \mathrm{~s}, \mathrm{PCR}$ reaction at $95^{\circ} \mathrm{C}$ for $5 \mathrm{~s}$, and collecting fluorescence at $55^{\circ} \mathrm{C}$ for $30 \mathrm{~s}$, with a total of 40 cycles, repeated three times.

\section{Results}

3.1. Meta-Analysis of Susceptibility Genes and Serum Markers. There were 176 documents about susceptibility and 216 documents about serum markers for initial survey after screening, there were 19 documents about susceptibility [12-31], and 20 documents about serum markers [32-51] were eventually included for meta-analysis.

Meta-analysis results of susceptibility genes and serum markers are shown in Tables 2 and 3. The heterogeneity test result of susceptibility genes NKX2.5 and FOG2 was $p>0.05$, indicating the consistency of the literatures was well, so fixed effect model was used to pool the data. The heterogeneity test result of GATA 4 was $p<0.05$, suggesting that heterogeneity existed between the literatures, so the random effect model was adopted. The upper and lower limit of pooled SMD and 95\% CI were greater than 1, indicating that the correlation between the mutation of three genes and congenital heart disease was statistical significance. The heterogeneity test result of three serum markers was $p<0.05$, indicating that heterogeneity existed between literatures, so the random effect model was adopted. The upper and lower limit of pooled WMD and 95\% CI were all greater than 0 . Additionally, 95\% CI transverse lines of three serum markers fell to the left side of the invalid vertical lines, suggesting that the incidence rate of the experimental group was bigger than that of the control group. Specific meta-analysis results are shown in Additional Files 1-6 (see Supplementary Material available online at http://dx.doi.org/10.1155/2016/9506829).
TABLE 1: Name, sequence, and product length of each primer.

\begin{tabular}{llc}
\hline Primer name & Primer sequence & Product length \\
\hline NKX2.5-F & AGAAGACAGAGGCGGACAAC & \multirow{2}{*}{$175 \mathrm{bp}$} \\
NKX2.5-R & CGTGGACGTGAGTTTCAGCA & \\
\hline GATA4-F & GTGTCCCAGACGTTCTCAGT & \multirow{2}{*}{$226 \mathrm{bp}$} \\
GATA4-R & TCCGTGCAGGAATTTGAGGA & \\
\hline FOG2-F & TTAATCAACGGAAGCAAATG & \multirow{2}{*}{$466 \mathrm{bp}$} \\
FOG2-R & CCACTCAAATACAGGGTTAGG & \\
\hline GAPDH-F & AGAAGGCTGGGGCTCATTTG & \multirow{2}{2}{$258 \mathrm{bp}$} \\
GAPDH-R & AGGGGCCATCCACAGTCTTC & \\
\hline
\end{tabular}

3.2. Test Results of Serum Markers. The test results of serum markers cTnI, hs-CRP, BNP, and Lp(a) of 80 patients with $\mathrm{CHD}$ and 80 healthy persons are shown in Figure 1. As can be seen from the figure, the levels of cTnI, hs-CRP, BNP, and $L p(a)$ in the case group were significantly higher than those in the controls $(p<0.05)$.

3.3. Logistic Regression Analysis Results. With cTnI, hs-CRP, $\mathrm{BNP}$, and $\mathrm{Lp}(\mathrm{a})$ as independent variables and sick or not as the dependent variable, SPSS19.0 was used for dichotomy Logistic regression analysis. Univariate regression analysis results are presented in Table 4, which suggested that the relationship between $\mathrm{Lp}(\mathrm{a}), \mathrm{BNP}$, and cTnI with $\mathrm{CHD}$ was statistically significant $(p<0.05)$. These three factors were then used for multivariate Logistic regression analysis. The results showed that the combination of these three factors was unfavorable for accurate diagnosis of $\mathrm{CHD}(p>$ 0.05 , Table 5). Pairwise combinations of three factors were conducted for multivariate Logistic regression analysis and the results are presented in Table 6 . It was indicated that the relationship between $\operatorname{Lp}(\mathrm{a}), \mathrm{BNP}$, and cTnI with CHD had statistical significance $(p<0.05)$. The accuracy rates of combined predication of $\mathrm{Lp}(\mathrm{a})$ and $\mathrm{cTnI}, \mathrm{Lp}(\mathrm{a})$ and BNP, and BNP and cTnI were $93.4 \%, 87.1 \%$, and $97.2 \%$, respectively.

3.4. Application Value Evaluation of Serum Markers on the Detection of CHD. SPSS19.0 software was adopted to evaluate the application value of $\mathrm{Lp}(\mathrm{a}), \mathrm{BNP}$, and cTnI combined detection of CHD. ROC curves are shown in Figure 2. The AUC of Lp(a) and cTnI, Lp(a) and BNP, and BNP and cTnI joint detection were $0.994,0.981$, and 0.999 , respectively, showing a high application value.

3.5. Establishing Relational Model of CHD Serum Markers Group Based on SVM. Serum markers cTnI, hs-CRP, BNP, and Lp (a) levels of $80 \mathrm{CHD}$ patients and 80 healthy controls undergone attributive analysis. It was indicated that attributive analysis had significant classification and the data were consistent with the basic calculation requirements of SVM (Figure 3).

The relational model of CHD serum markers group based on SVM was established. Then, the test data of $20 \mathrm{CHD}$ patients and 20 healthy controls were input into it. The test results are shown in Figure 4. The hollow circles represent the 
TABLE 2: Meta-analysis results of susceptibility genes.

\begin{tabular}{|c|c|c|c|c|c|}
\hline \multirow{2}{*}{ Susceptibility gene } & \multirow{2}{*}{ Number of documents } & \multicolumn{2}{|c|}{ Heterogeneity test } & \multirow{2}{*}{ OR } & \multirow{2}{*}{$95 \% \mathrm{CI}$} \\
\hline & & $I^{2}$ & $p$ & & \\
\hline NKX2.5 & 7 & $36 \%$ & 0.16 & 2.02 & $1.42-2.86$ \\
\hline GATA4 & 11 & $58 \%$ & 0.01 & 2.08 & $1.50-2.88$ \\
\hline FOG2 & 4 & $0 \%$ & 0.85 & 19.43 & $4.52-83.63$ \\
\hline
\end{tabular}

TABLE 3: Meta-analysis of serum markers.

\begin{tabular}{lccccc}
\hline \multirow{2}{*}{ Serum markers } & \multirow{2}{*}{ Number of documents } & \multicolumn{2}{c}{ Heterogeneity test } & \multicolumn{2}{c}{ WMD } \\
\hline cTnI & 4 & $I^{2}$ & $p$ & $95 \%$ CI \\
hs-CRP & 8 & $99.2 \%$ & 0.000 & 0.33 & $0.12 \sim 0.55$ \\
BNP & 19 & $87.5 \%$ & 0.000 & 1.84 & $1.36 \sim 2.32$ \\
\hline
\end{tabular}

TABLE 4: Univariate regression analysis of serum markers associated with CHD.

\begin{tabular}{lccccc}
\hline $\begin{array}{l}\text { Serum } \\
\text { markers }\end{array}$ & $B$ & SE & Wals & Sig. & $\operatorname{Exp}(B)$ \\
\hline Lp(a) & 0.036 & 0.006 & 40.422 & 0.000 & 1.036 \\
BNP & 0.478 & 0.077 & 38.954 & 0.000 & 1.612 \\
hs-CRP & 83.858 & 400.679 & 0.044 & 0.834 & $2.625 E 36$ \\
cTnI & 172.096 & 37.484 & 21.079 & 0.000 & $5.502 E 74$ \\
\hline
\end{tabular}

TABLE 5: Three-factor multivariate regression analysis of serum markers associated with CHD.

\begin{tabular}{lccccc}
\hline $\begin{array}{l}\text { Serum } \\
\text { markers }\end{array}$ & $B$ & SE & Wals & Sig. & $\operatorname{Exp}(B)$ \\
\hline Lp(a) & 0.046 & 52.695 & 0.018 & 0.869 & 1.047 \\
BNP & 156.787 & 72890.460 & 0.008 & 0.924 & 1.235 \\
cTnI & 0.665 & 152.952 & 0.000 & 0.997 & 1.944 \\
\hline
\end{tabular}

TABLE 6: Two-factor multivariate regression analysis of serum markers associated with CHD.

\begin{tabular}{ccccccc}
\hline & $\begin{array}{c}\text { Serum } \\
\text { markers }\end{array}$ & $B$ & SE & Wals & Sig. & $\operatorname{Exp}(B)$ \\
\hline 1 & Lp(a) & 0.045 & 0.011 & 15.672 & 0.000 & 1.046 \\
& BNP & 0.508 & 0.114 & 19.774 & 0.000 & 1.662 \\
\hline \multirow{2}{*}{2} & Lp(a) & 0.043 & 0.012 & 11.876 & 0.001 & 1.044 \\
& cTnI & 211.657 & 61.321 & 11.914 & 0.001 & $8.348 E 91$ \\
\hline \multirow{2}{*}{3} & BNP & 0.682 & 0.247 & 7.619 & 0.006 & 1.978 \\
& cTnI & 263.631 & 111.283 & 5.612 & 0.018 & $3.115 E 114$ \\
\hline
\end{tabular}

target output; "*” is the actual simulation output of SVM. As can be seen from the figure, the diagnostic accuracy of the model was $34 / 40=85 \%$.

3.6. GO Functional Annotation Results Comparison between Susceptibility Genes and Serum Markers of CHD. After comparing the GO functional annotation results of susceptibility genes NKX2.5, GATA4, and FOG2 and serological indicators hs-CRP, Lp(a), BNP, and cTnI, it was found that NKX2.5,
GATA4, and FOG2 had same GO functional annotation with $\operatorname{Lp}(\mathrm{a})$ and BNP. The functional relations between three susceptibility genes and BNP were mainly in gene expression and metabolic process. The internal connections between Lp(a) and NKX2.5, GATA4, and FOG2 were mainly in function, especially in the aspects of Lipoprotein transmembrane transport and blood circulation. The same GO functional annotations of them are shown in Tables 7-9.

3.7. Relative Expression Contents of Susceptibility Genes in $m R N A$ Level. Real-time fluorogenic quantitative PCR was used to detect the expression levels of susceptibility genes NKX2.5, GATA4, and FOG2 in mRNA. $2^{-\Delta \Delta \mathrm{Ct}}$ was used to calculate the relative expression levels, and the results were $0.59 \pm 0.18,0.47 \pm 0.14$, and $0.33 \pm 0.09$, respectively. If the content of the control group was 1 , the relative expression levels of NKX2.5, GATA4, and FOG2 in the case group were $0.59 \pm 0.18,0.47 \pm 0.14$, and $0.33 \pm 0.99$, respectively (Figure 5). The expression levels of susceptibility genes NKX2.5, GATA4, and FOG2 in the case group were obviously lower than those in the controls. The results of serum indexes detection showed that $\mathrm{Lp}(\mathrm{a})$ and BNP levels in the case group were significantly higher than those in the controls (Figure 1). Thus it can be inferred that the unusual increase of serum Lp(a) and BNP levels may be related to the abnormal expression of NKX2.5, GATA4, and FOG2 genes.

\section{Discussion}

CHD is the most common congenital malformation at present and also the leading cause of infant death. Many factors interact with each other temporally and spatially in the development of heart. The combined actions of hereditary and environmental factors in embryonic phase will lead to the dysplasia of heart. Due to the complex genetic mechanism of $\mathrm{CHD}$, the reason resulting in the malformation of heart is still unclear. The type of CHD is diverse, which has become a big problem in the treatment and prevention of CHD.

In this study, meta-analysis found that the mutation of NKX2.5, GATA4, and FOG2 genes played an important role in the development of CHD. The mutation of NKX2.5 


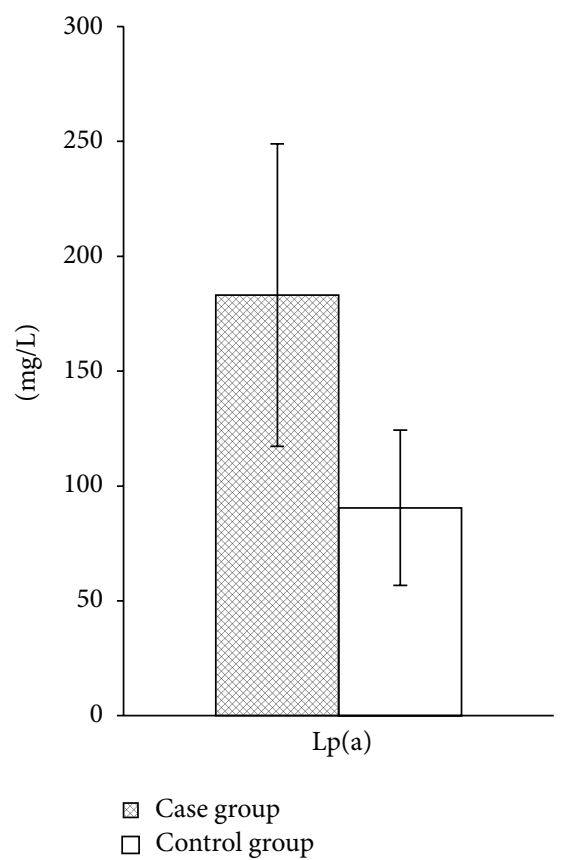

(a)

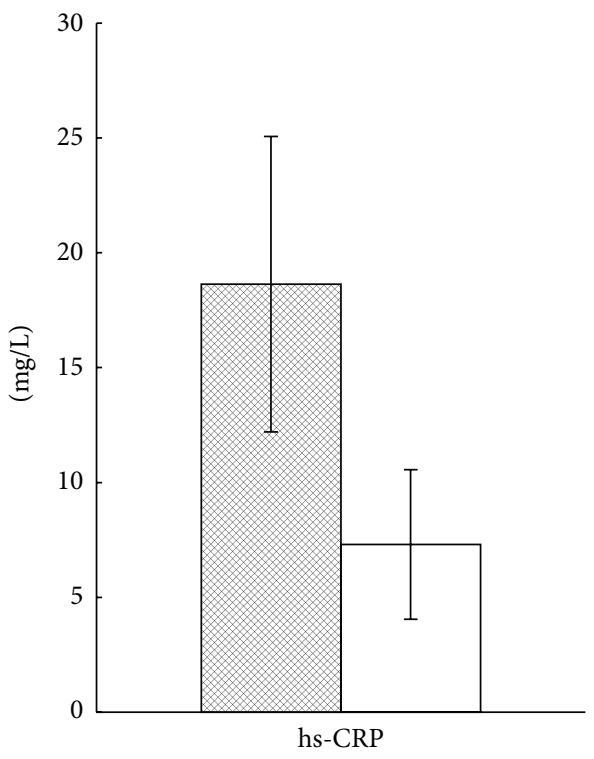

종 group

$\square$ Control group

(c)

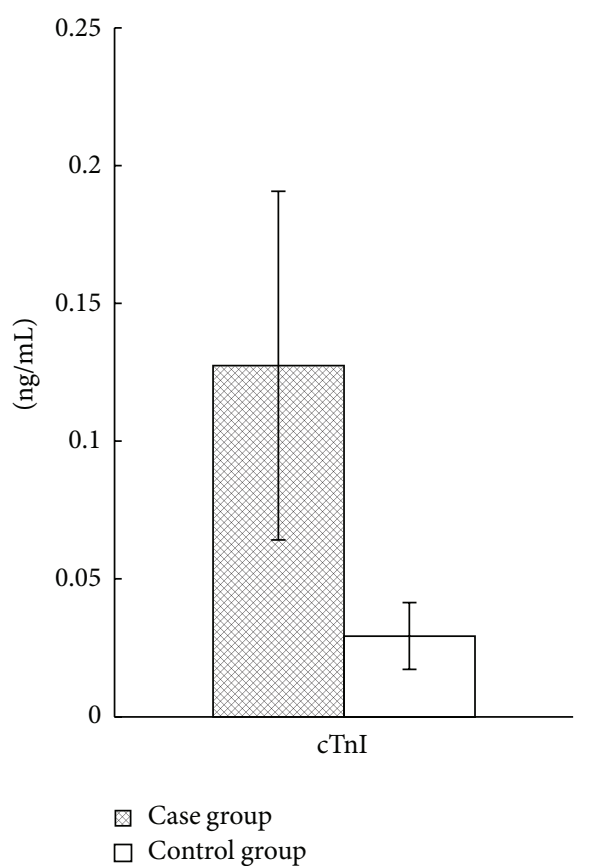

(b)

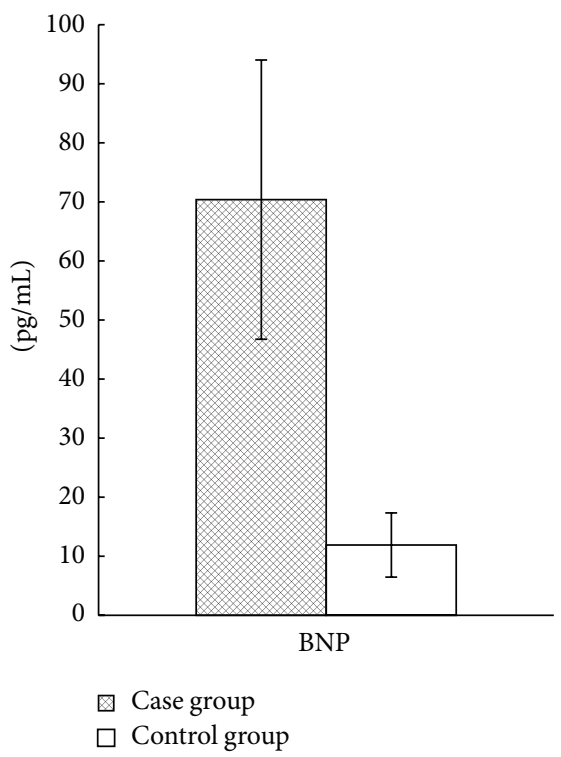

(d)

FIgURE 1: Detection results of four serum markers of CHD patients. * indicates $p<0.05$.

gene occurred mainly in homeodomain structural domain. McElhinney et al. [52] reported that the mutation of exon 1 of NKX2.5 gene existed in various CHD. The pathological and physiological effects of GATA4 gene related to heart development have been extensively researched. Garg et al. [53] have verified that GATA4 gene mutation is one of the causes of $\mathrm{CHD}$ for the first time by the molecular genetics research on two independent and simple CHD families. FOG2 gene is a transcription factor with early expression in the process of heart development. Its interaction with GATA4 runs through the entire process of heart development. FOG2 plays an essential role in the development process of heart [3]. Both Tan and De Luca found a mutation in FOG2 gene exon from patients with double-outlet right ventricle combined ventricular septal defect [30,31]. This paper found that serum markers cTnI, hs-CRP, and BNP were related to CHD and they can predict the occurrence of the disease. Guo [32] believed that the changes in serum levels of cTnI were of 


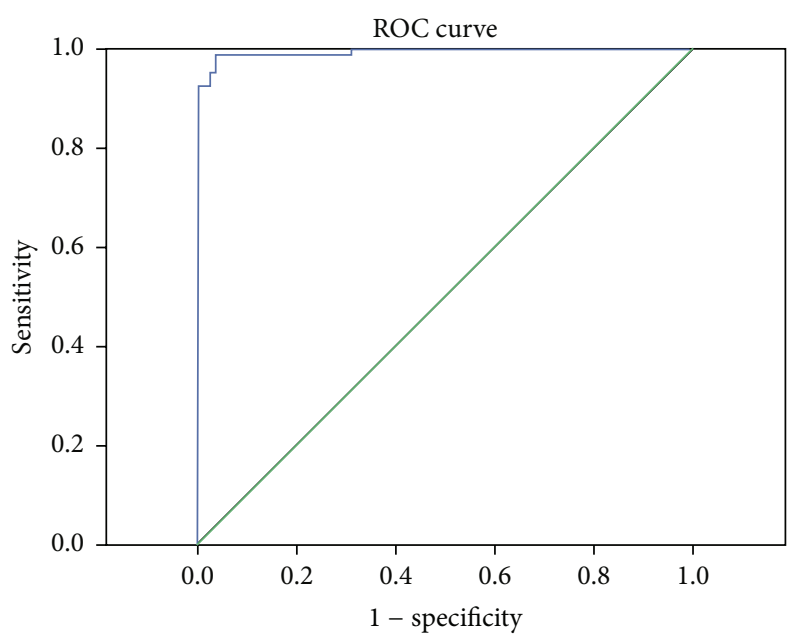

(a)

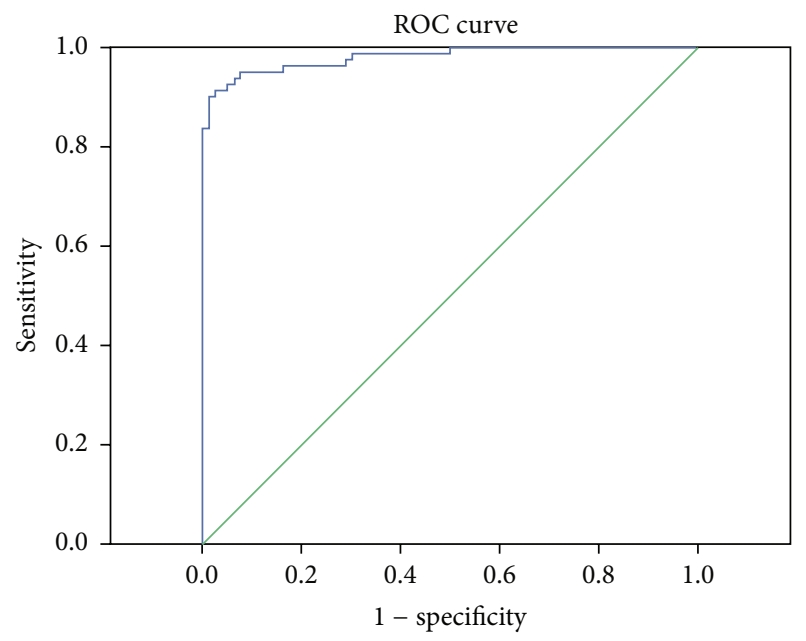

(b)

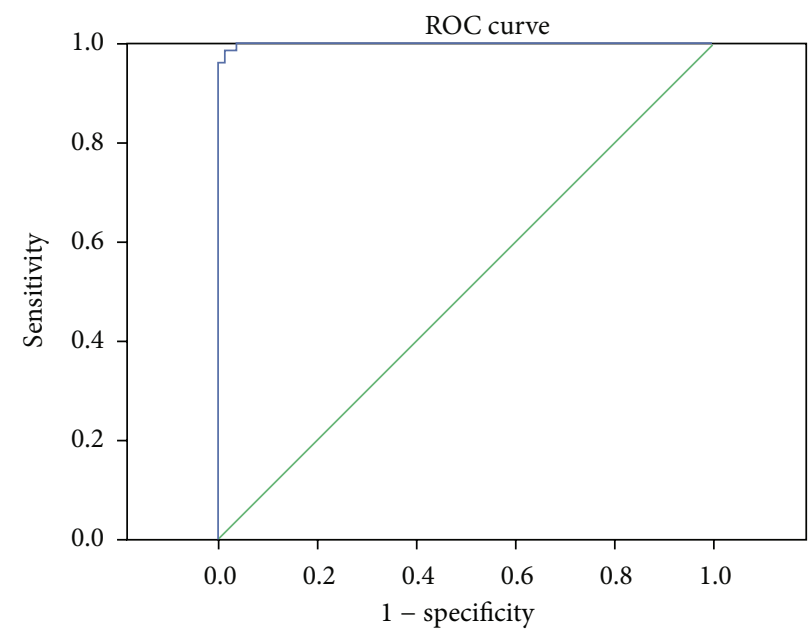

(c)

Figure 2: ROC curve of combined detection of CHD. (a) Lp(a) and cTnI; (b) Lp(a) and BNP; (c) BNP and cTnI.

great value in understanding the state and prognosis of CHD. However, researches on the relationship between $\operatorname{Lp}(\mathrm{a})$ and $\mathrm{CHD}$ were much rare, and $\mathrm{Lp}(\mathrm{a})$ did not meet the condition of meta-analysis, so we could not perform analysis of this factor.

By examining the levels of cTnI, hs-CRP, BNP, and Lp(a) of 80 CHD patients and 80 healthy control subjects, this study showed that the levels of cTnI, hs-CRP, BNP, and $\operatorname{Lp}(\mathrm{a})$ in the case group were significantly higher than those in the controls, and the difference was statistically significant. Geiger et al. [54] found that, compared to the non-CHD subjects, $\mathrm{BNP}$ level of $\mathrm{CHD}$ children was obviously increased.. Similarly, Akhabue et al. [55] also believe that the difference of BNP concentration between CHD children patients and non-CHD children was significant. A number of studies show that the relationship between LP(a) and atherosclerotic disease was close, and the increased LP(a) is an independent risk factor of cardiovascular events [5659]. Guo [32] has shown that serum cTnI level in patients with CHD was significantly higher than that in normal people. Logistic regression analysis showed that there existed significant correlations between cTnI, BNP, Lp(a), and CHD. When performing combined diagnosis, cTnI, BNP, and Lp(a) pairwise binding were associated with $\mathrm{CHD}$. According to the joint detection ROC curve, it was found that the pairwise combination AUC of cTnI, BNP, and $\mathrm{Lp}(\mathrm{a})$ were greater than 0.9 , and the accuracy rates were higher than $87 \%$. The bigger the data is, the better the effect is when using Logistic regression model. SVM in contrast has a higher accuracy rate as to small sample size.

Recent studies showed that GATA4 and GATA6 can collaborate and regulate the expression of brain natriuretic peptide (BNP). The deletion of any factor of GATA will lead to the downregulation of BNP level [60]. Other studies indicated that NKX2.5 and FOG2 could cooperate with GATA4, all of which play an important role in the normal process of heart development [61, 62]. As an independent protein molecule having a specific antigenicity, the metabolic pathways of $\mathrm{Lp}(\mathrm{a})$ is completely different from other apolipoproteins. It can interfere with lipid metabolism and the fibrinolytic system and then play an important role in cardiovascular diseases 


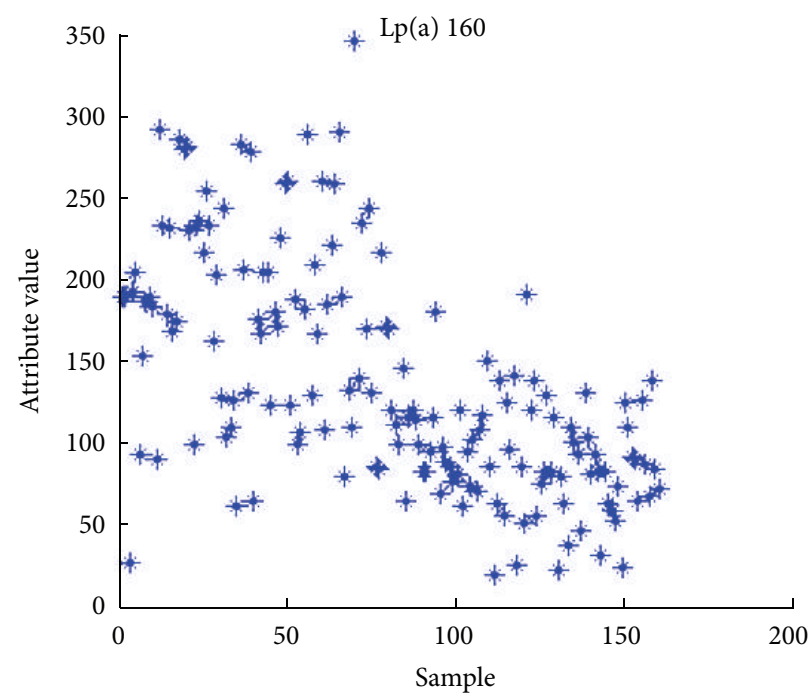

(a)

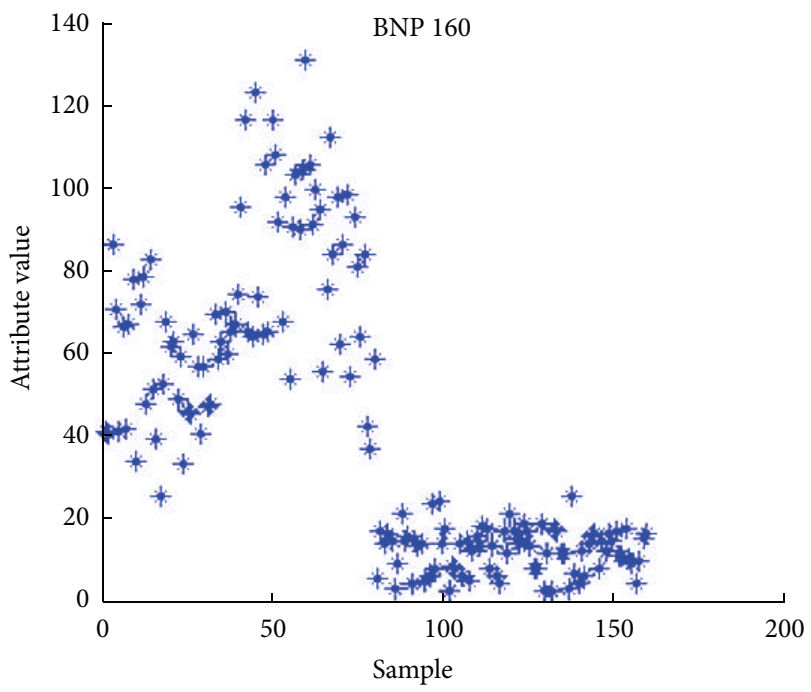

(c)

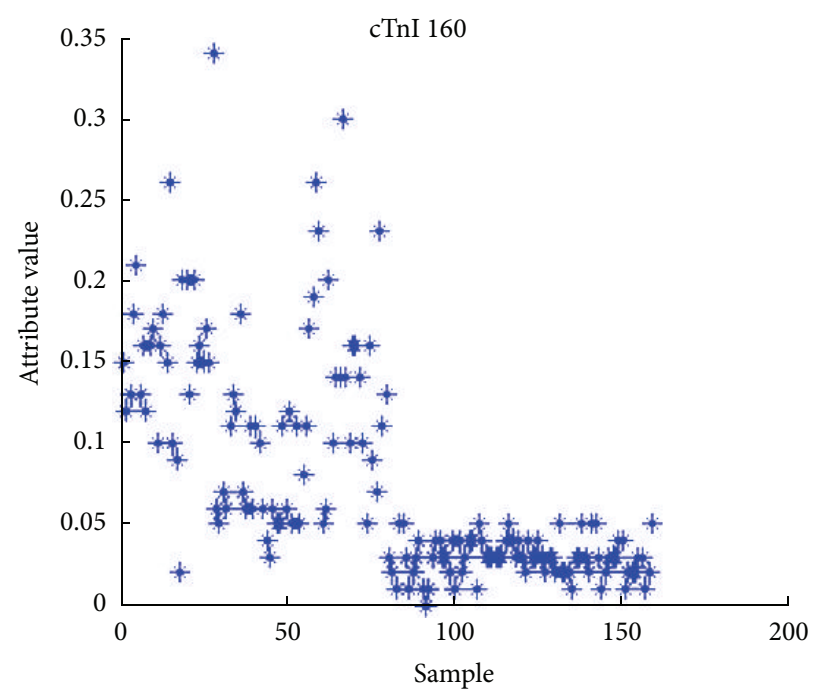

(b)

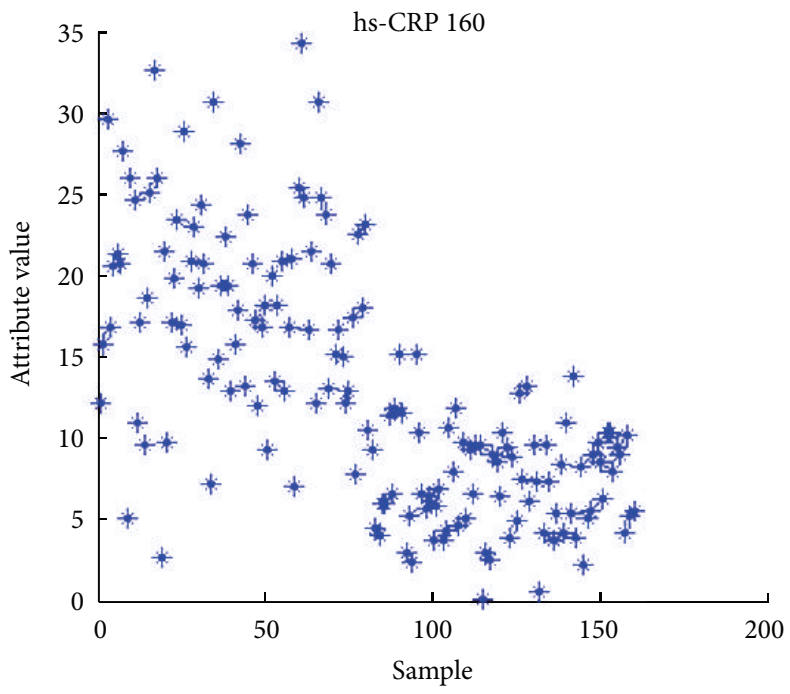

(d)

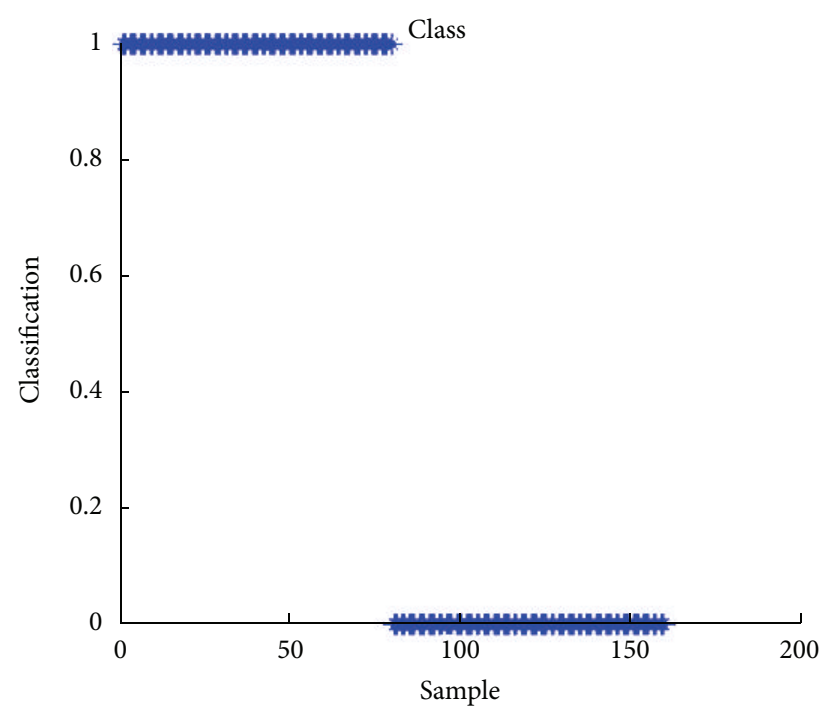

(e)

FIgURE 3: Attribution analyses of four serum markers of CHD. 


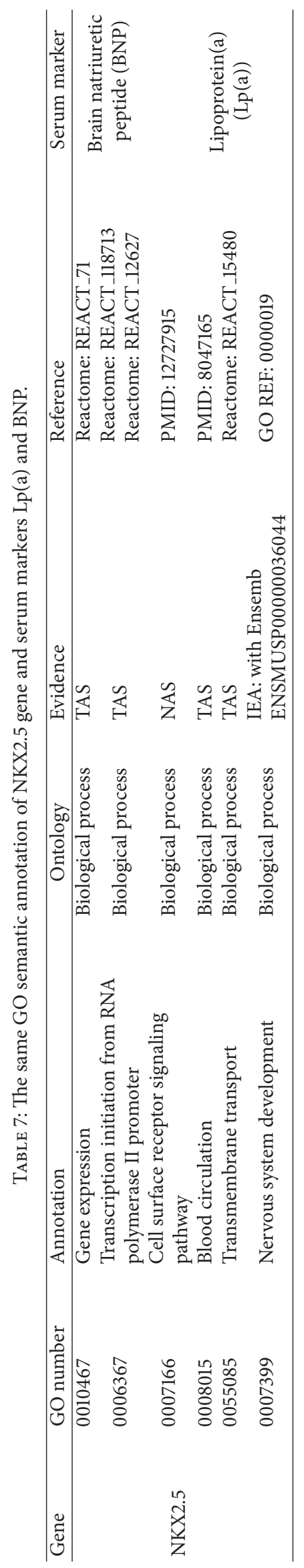




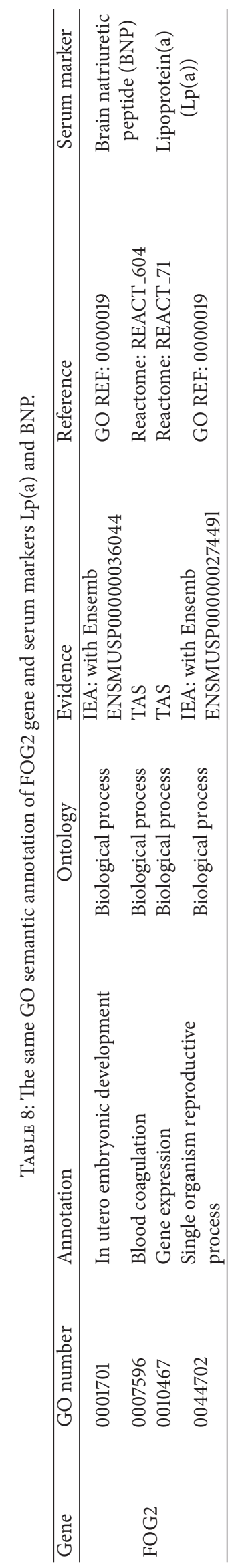




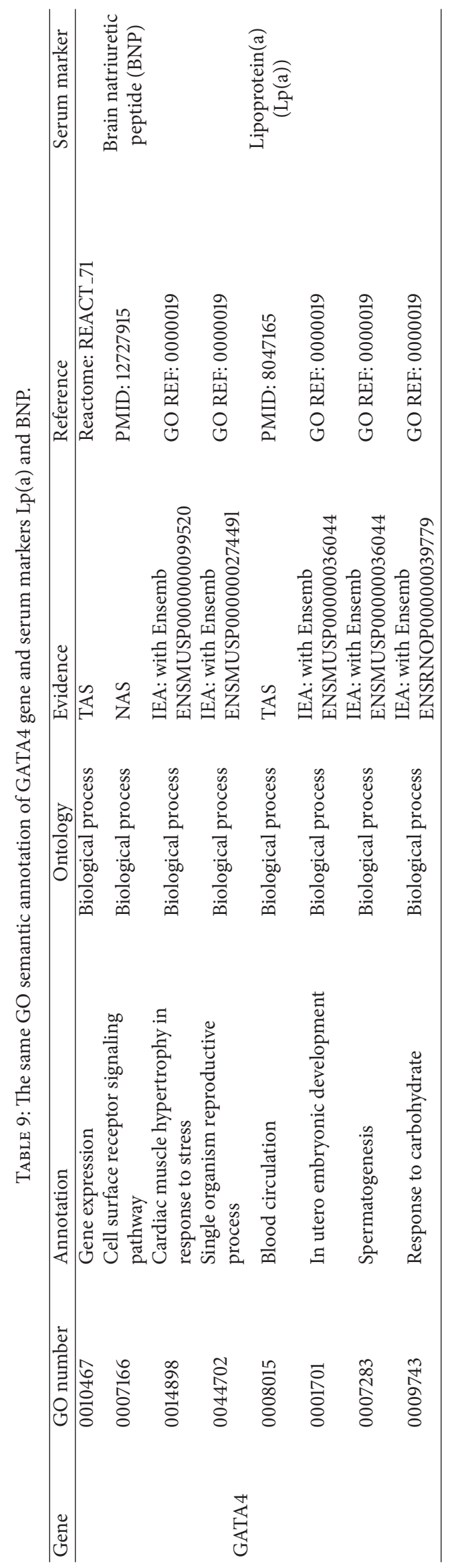




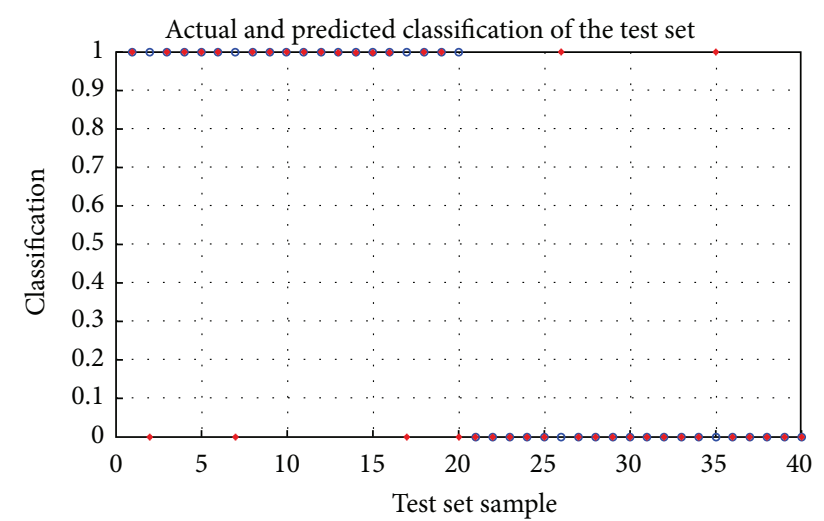

- Actual test set classification

- Predicted test set classification

FIGURE 4: Relational model of CHD markers group based on SVM.

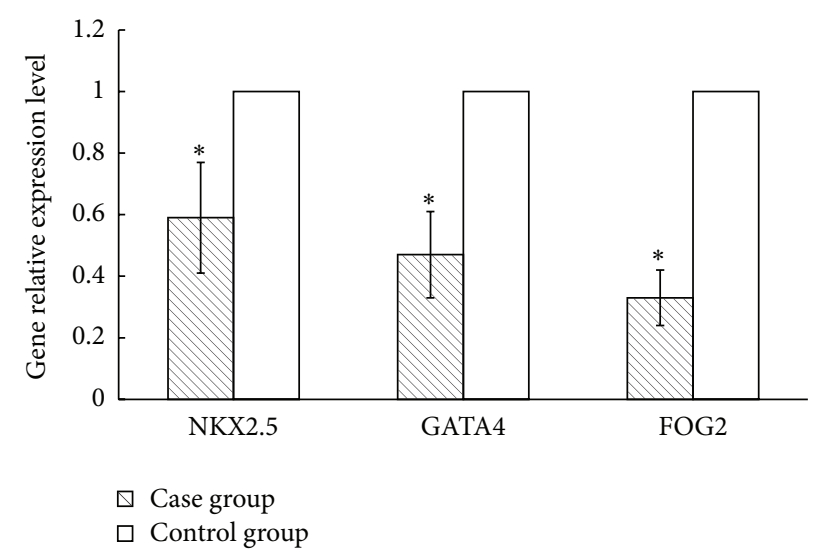

FIGURE 5: The relative expression levels of CHD susceptibility genes. * indicates $p<0.05$.

like thrombosis and atherosclerosis [63, 64]. Studies have shown that $\mathrm{Lp}(\mathrm{a})$ is an independent risk factor for myocardial infarction, coronary heart disease, and other cardiovascular diseases [65-68], but few researches are conducted on the relationship between $\mathrm{Lp}(\mathrm{a})$ and $\mathrm{CHD}$. At present, it is not reported which transcription factor $\operatorname{Lp}(\mathrm{a})$ is regulated by. By bioinformatics analysis, this study showed that there were the same GO functional annotations between susceptibility gene NKX2.5, GATA4, and FOG2 and Lp(a) and BNP. The links between susceptibility genes and BNP existed mainly in gene expression and metabolism. Lp(a), especially in Lipoprotein membrane transport and blood circulation, was intrinsically linked to NKX2.5, GATA4, and FOG2. This paper conducted a study on the mRNA relative expression levels of susceptibility genes, $\operatorname{Lp}(a)$ and BNP. It was indicated that the levels of NKX2.5, GATA4, and FOG2 of the case group were significantly lower than those of the controls. The contents of $\operatorname{Lp}(\mathrm{a})$ and BNP of the case group were significantly higher than those of the controls, suggesting that the abnormal expression of susceptibility genes may lead to the increase of BNP level. However, the mechanism which causes the abnormal expression of $\operatorname{Lp}(\mathrm{a})$ is still not clear, so further study is required. This also gives us a direction on the in-depth study of CHD.

\section{Conclusions}

In conclusion, as risk factors associated with $\mathrm{CHD}$, cTnI, CRP, BNP and Lp(a) also have functional relation with susceptibility genes; therefore, they may provide a basis for the clinical detection of CHD, but its specific application still requires a lot of clinical cases data to train and optimize, thus making it more accurate. Clinical auxiliary testing model is only as an auxiliary tool at the early stage and cannot completely replace an experienced clinician's diagnosis. The clinical diagnosis of CHD still needs to integrate all aspects of judgments.

\section{Ethical Approval}

We certify that this study has followed the Declaration of Helsinki (1964).

\section{Consent}

All subjects have given their written informed consent.

\section{Conflict of Interests}

The authors declare that there is no conflict of interests regarding the publication of this paper.

\section{Acknowledgments}

The authors of this paper thank all authors who have contributed to it for advice and comments and thank Dr. Zhang for technical expertise. This study was supported by Funds 20120900, 20130459, and 132102310332 and the National Natural Science Foundation of China (Grant 81303150).

\section{References}

[1] S. Malik, M. A. Cleves, M. A. Honein et al., "Maternal smoking and congenital heart defects," Pediatrics, vol. 121, no. 4, pp. e810e816, 2008.

[2] P. Dadvand, J. Rankin, S. Rushton, and T. Pless-Mulloli, "Association between maternal exposure toambient air pollution and congenital heart disease: a register-based sptiotemporal analysis," American Journal of Epidemiology, vol. 173, no. 2, pp. 171-182, 2011.

[3] R. Kučiene and V. Dulskiene, "Parental cigarette smoking and the risk of congenital heart septal defects," Medicina, vol. 46, no. 9, pp. 635-641, 2010.

[4] A. Miller, T. Riehle-Colarusso, C. Siffel, J. L. Frías, and A. Correa, "Maternal age and prevalence of isolated congenital heart defects in an urban area of the United States," American Journal of Medical Genetics A, vol. 155, no. 9, pp. 2137-2145, 2011.

[5] L. A. Lisowski, P. M. Verheijen, J. A. Copel et al., "Congenital heart disease in pregnancies complicated by maternal diabetes mellitus: an international clinical collaboration, literature review, and meta-analysis," Herz, vol. 35, no. 1, pp. 19-26, 2010. 
[6] L. L. Lipscombe, A. T. Banerjee, S. McTavish et al., "Readiness for diabetes prevention and barriers to lifestyle change in women with a history of gestational diabetes mellitus: rationale and study design," Diabetes Research and Clinical Practice, vol. 106, no. 1, pp. 57-66, 2014.

[7] B. Pejtsik, J. Pintér, M. Horváth, and J. Hadnagy, "Relationship between congenital heart disease and various factors affecting pregnancy," Orvosi Hetilap, vol. 133, no. 3, pp. 155-158, 1992.

[8] P. Pradat, C. Francannet, J. A. Harris, and E. Robert, "The epidemiology of cardiovascular defects, part I: a study based on data from three large registries of congenital malformations," Pediatric Cardiology, vol. 24, no. 3, pp. 195-221, 2003.

[9] Z. Hu, X. Yuan, K. Rao, Z. Zheng, and S. Hu, "National trend in congenital heart disease mortality in China during 2003 to 2010: a population-based study," Journal of Thoracic and Cardiovascular Surgery, vol. 148, no. 2, pp. 596-602, 2014.

[10] V. N. Vapnik, The Nature of Statistical Learning Theory, Springer, Berlin, Germany, 2nd edition, 1999.

[11] X. Song and N.-K. Chen, "A SVM-based quantitative fMRI method for resting-state functional network detection," Magnetic Resonance Imaging, vol. 32, no. 7, pp. 819-831, 2014.

[12] S. Pikkarainen, H. Tokola, R. Kerkelä, and H. Ruskoaho, "GATA transcription factors in the developing and adult heart," Cardiovascular Research, vol. 63, no. 2, pp. 196-207, 2004.

[13] M. Zhao, X. Y. Zhu, X. L. Tian et al., "Detection of mutation in ZFPM2/FOG2 gene coding region in patients of Tetralogy of Fallot," Chinese Journal of Cardiovascular Research, vol. 10, pp. 422-424, 2012.

[14] W. Huang, H. Meng, Y. Qiao, S. Pang, D. Chen, and B. Yan, "Two novel and functional DNA sequence variants within an upstream enhancer of the human NKX2-5 gene in ventricular septal defects," Gene, vol. 524, no. 2, pp. 152-155, 2013.

[15] F. Xiong, Q. Li, C. Zhang et al., "Analyses of GATA4, NKX2.5, and TFAP2B genes in subjects from southern China with sporadic congenital heart disease," Cardiovascular Pathology, vol. 22, no. 2, pp. 141-145, 2013.

[16] S. Pang, J. Shan, Y. Qiao et al., "Genetic and functional analysis of the NKX2-5 gene promoter in patients with ventricular septal defects," Pediatric Cardiology, vol. 33, no. 8, pp. 1355-1361, 2012.

[17] X. Fang, Exploration of the Transcription Factor NKX2.5 and GATA4 in Patients with Congenital Heart Disease, Southeast University, 2011.

[18] T. Peng, L. Wang, S.-F. Zhou, and X. Li, "Mutations of the GATA4 and NKX2.5 genes in Chinese pediatric patients with non-familial congenital heart disease," Genetica, vol. 138, no. 11, pp. 1231-1240, 2010.

[19] J.-D. Ding, K.-R. Li, X.-L. Zhang et al., "Preliminary exploration of transcription factor Nkx2.5 mutations and congenital heart diseases," National Medical Journal of China, vol. 89, no. 16, pp. 1114-1116, 2009.

[20] K. R. Li, J. D. Ding, X. L. Zhang, Y. Y. Yao, L. Q. Ren, and G. S. Ma, "Observation of transcription factor Nkx2.5 mutations of congenital heart disease patients," Shandong Medical Journal, vol. 48, pp. 83-84, 2008.

[21] C. Cheng, Y. Lin, F. Yang et al., "Mutational screening of affected cardiac tissues and peripheral blood cells identified novel somatic mutations in GATA4 in patients with ventricular septal defect," Journal of Biomedical Research, vol. 25, no. 6, pp. 425-430, 2011.

[22] W.-M. Zhang, X.-F. Li, Z.-Y. Ma et al., "GATA4 and NKX2.5 gene analysis in Chinese Uygur patients with congenital heart disease," Chinese Medical Journal, vol. 122, no. 4, pp. 416-419, 2009.

[23] B. B. Dong, G. F. Zheng, H. Zhao, D. Wei, and X. Y. Liu, "Mutational analysis of the GATA4 gene in patients with congenital heart disease," International Journal of Cardiovascular Disease, vol. 39, pp. 48-52, 2012.

[24] Y. Q. Yang, Y. Q. Tang, and X. Y. Liu, "A novel GATA4 mutation leading to congenital heart disease ventricular septal defect," Chinese Journal of Medical Genetics, vol. 27, pp. 512-516, 2010.

[25] X. Y. Liu, Y. Q. Yang, J. Ma, X. P. Lin, and Y. H. Chen, "Novel GATA4 mutations in patients with congenital ventricular septal defects," Chinese Journal of Laboratory Medicine, vol. 33, pp. 343-347, 2010.

[26] X. P. Lin and Y. H. Chen, "GATA4 mutations and sporadic congenital heart disease," Journal of Tongji University, vol. 30, pp. 9-13, 2009.

[27] M. W. Chen, Screening and Functional Analysis of GATA4 Mutations in Congenital Cardiac Septal Defects, Guangxi Medical University, 2009.

[28] Z.-H. Tang, L. Xia, W. Chang et al., "Two novel missense mutations of GATA4 gene in Chinese patients with sporadic congenital heart defects," Zhonghua Yi Xue Yi Chuan Xue Za Zhi, vol. 23, no. 2, pp. 134-137, 2006.

[29] W. Zhang, L. Shen, Z. Deng et al., "Novel missense variants of ZFPM2/FOG2 identified in conotruncal heart defect patients do not impair interaction with GATA4," PLoS ONE, vol. 9, no. 7, Article ID e102379, 2014.

[30] Z.-P. Tan, C. Huang, Z.-B. Xu, J.-F. Yang, and Y.-F. Yang, "Novel ZFPM2/FOG2 variants in patients with double outlet right ventricle," Clinical Genetics, vol. 82, no. 5, pp. 466-471, 2012.

[31] A. De Luca, A. Sarkozy, R. Ferese et al., "New mutations in ZFPM2/FOG2 gene in tetralogy of Fallot and double outlet right ventricle," Clinical Genetics, vol. 80, no. 2, pp. 184-190, 2011.

[32] Y. Guo, "Clinical value of heart color-ultrasonography combined measurement of serum cTnI, IGF-I and IGFBP-3 levels in patients with congenital heart diseases," Journal of Radioimmunology, vol. 24, no. 5, pp. 500-502, 2011.

[33] H. Sha, Q. Li, W. Qian, H. Li, and G. Q. Chen, "Evaluation of cardiac function by H-FABP, NT-proBNP, cTnI in children with congenital heart diseases and pneumonia," Chinese Journal of Pediatrics, vol. 29, pp. 939-941, 2011.

[34] A. Uner, M. Doğan, M. Ay, and Ç. Acar, "The evaluation of serum $N$-terminal prohormone brain-type natriuretic peptide, troponin-I, and high-sensitivity C-reactive protein levels in children with congenital heart disease," Human and Experimental Toxicology, vol. 33, no. 11, pp. 1158-1166, 2014.

[35] F.-J. Zhou, C.-Y. Zhou, Y.-J. Tian et al., "Diagnostic value of analysis of H-FABP, NT-proBNP, and cTnI in heart function in children with congenital heart disease and pneumonia," European Review for Medical and Pharmacological Sciences, vol. 18, no. 10, pp. 1513-1516, 2014.

[36] H. Tomita, M. Takamuro, W. Soda, K. Hatakeyama, and H. Tsutsumi, "Increased serum high-sensitivity C-reactive protein is related to hypoxia and brain natriuretic peptide in congenital heart disease," Pediatrics International, vol. 50, no. 4, pp. 436440, 2008.

[37] X. F. Guang, H. L. Dai, C. H. Zhang et al., "Study of the changes of serum BNP, VEGF, and hs-CRP in patients with congenital heart disease combined with pulmonary arterial hypertension," Chinese Journal of Clinicians, vol. 6, pp. 891-893, 2012. 
[38] S. Yang, Clinical Research of the Value of Measurement of Plasma Brain Natriuretic Peptide and High Sensitive C-Reactive Protein in Congenital Heart Disease, Hebei Medical University, 2012.

[39] X. J. Zhao, Y. L. Geng, Z. L. Chen, G. X. Wang, J. Zhao, and X. B. Li, "Clinical analysis of serum hs-CRP and BNP levels of children with blue type congenital heart disease," Hebei Medical Journal, vol. 36, pp. 1790-1792, 2014.

[40] W. Li, Clinical significance and changes in copeptin, brain natriuretic peptide and C-reactive protein concentration on peripheral blood in children with congenital heart disease combined with heart failure [M.S. thesis], Qingdao University, Qingdao, China, 2014.

[41] X. N. Wang, S. B. Yang, X. Y. Tian et al., "Clinical value of C-reactive protein combined with B-type natriuretic peptide in evaluation of cardiac function of congenital heart disease children with pulmonary infections," Chinese Journal of Nosocomiology, vol. 24, pp. 1263-1264, 2014.

[42] X. L. Lin and H. P. Liu, "Clinical analysis of C-reactive protein and B-type natriuretic peptide assessment of cardiac function in congenital heart disease children with lung infections," The Journal of Medical Theory \& Practice, vol. 27, pp. 2001-2002, 2014.

[43] Y. Qiu, X. L. Huang, J. Wu, H. Zheng, W. S. Wu, and Z. Lin, "Plasma brain natriuretic peptide and Tei index assessment of heart function in children with left to right congenital heart defects," Maternal and Child Health Care of China, vol. 22, pp. 2209-2211, 2007.

[44] B. Y. Meng, T. Wang, Q. Zhang et al., "Brain natriuretic peptide and Tei-index for assessing preoperative left heart function in infants with congenital heart diseases," South China Journal of Cardiovascular Diseases, vol. 16, pp. 378-381, 2010.

[45] J. Hu, H. Sha, and Q. Li, "The change of serum levels of B-type natriuretic peptides and the correlation to children with congenital heart disease and serious pnenmonia," Chinese Medicine, vol. 6, pp. 1402-1403, 2011.

[46] X. Li, M. Y. Yang, J. T. Qin, Y. Lin, D. Wang, and C. Y. Wang, "Relationship of serum N-terminal pro-brain natriuretic peptide and pulmonary artery pressure in pediatric patients with congenital heart disease," Hainan Medical Journal, vol. 23, no. 1, pp. 84-85, 2012.

[47] X. Li, M. Y. Yang, J. T. Qin et al., "Clinical significance of changes of plasma N-terminal pro-brain natriuretic peptide in children with congenital heart disease combined with heart failure," Journal of Applied Clinical Pediatrics, vol. 27, pp. 19-20, 2012.

[48] H. L. Wang and X. R. A, "Clinical significance of plasma BNP testing of children with congenital heart disease in plateau area," Laboratory Medicine, vol. 28, pp. 865-866, 2013.

[49] M. Kavga, G. Varlamis, A. Giannopoulos et al., "Correlation of plasma B-type natriuretic peptide with shunt volume in children with congenital heart disease involving left-to-right shunt," Hellenic Journal of Cardiology, vol. 54, no. 3, pp. 192-198, 2013.

[50] J. M. Fang, W. Guo, J. Jiang, L. F. Yu, and Y. Y. Guo, "Symptoms and clinical significance of $\mathrm{N}$-terminal pro-brain natriuretic peptide in children suffering from congenital heart disease combined with heart failure," China Medical Herald, vol. 10, pp. 43-45, 2013.

[51] C.-W. Lin, X.-L. Zeng, X.-H. Meng, S.-H. Jiang, and H. Ou-Yang, "Clinical importance of preoperative measurement of plasma amino-terminal pro-B-type natriuretic peptide in infants with congenital heart disease," Chinese Journal of Contemporary Pediatrics, vol. 16, no. 1, pp. 40-43, 2014.

[52] D. B. McElhinney, E. Geiger, J. Blinder, D. W. Benson, and E. Goldmuntz, "NKX2.5 mutations in patients with congenital heart disease," Journal of the American College of Cardiology, vol. 42, no. 9, pp. 1650-1655, 2003.

[53] V. Garg, I. S. Kathiriya, R. Barnes et al., "GATA4 mutations cause human congenital heart defects and reveal an interaction with TBX5," Nature, vol. 424, no. 6947, pp. 443-447, 2003.

[54] R. Geiger, A. Hammerer-Lercher, C. Url et al., "NT-proBNP concentrations indicate cardiac disease in pediatric patients," International Journal of Cardiology, vol. 123, no. 1, pp. 63-65, 2007.

[55] E. Akhabue, J. Thiboutot, J.-W. Cheng et al., "New and emerging risk factors for coronary heart disease," The American Journal of the Medical Sciences, vol. 347, no. 2, pp. 151-158, 2014.

[56] A. Bennet, E. Di Angelantonio, S. Erqou et al., "Lipoprotein(a) levels and risk of future coronary heart disease: large-scale prospective data," Archives of Internal Medicine, vol. 168, no. 6, pp. 598-608, 2008.

[57] P. R. Kamstrup, M. Benn, A. Tybjærg-Hansen, and B. G. Nordestgaard, "Extreme lipoprotein(a) levels and risk of myocardial infarction in the general population: the Copenhagen City Heart Study," Circulation, vol. 117, no. 2, pp. 176-184, 2008.

[58] Y. Momiyama, R. Ohmori, Z. A. Fayad et al., "Associations between serum lipoprotein(a) levels and the severity of coronary and aortic atherosclerosis," Atherosclerosis, vol. 222, no. 1, pp. 241-244, 2012.

[59] Y. Jiang, K. Guo, M. Chen, J. Bao, C. Shen, and Y. Li, "Serum lipoprotein(a) positively correlates with coronary artery calcification in low-risk Chinese Han patients: a study from a single center," PLoS ONE, vol. 8, no. 8, Article ID e71673, 2013.

[60] F. Charron, P. Paradis, O. Bronchain, G. Nemer, and M. Nemer, "Cooperative interaction between GATA-4 and GATA6 regulates myocardial gene expression," Molecular and Cellular Biology, vol. 19, no. 6, pp. 4355-4365, 1999.

[61] M. Salazar, F. Consoli, V. Villegas et al., "Search of somatic GATA4 and NKX2.5 gene mutations in sporadic septal heart defects," European Journal of Medical Genetics, vol. 54, no. 3, pp. 306-309, 2011.

[62] T. M. Chlon and J. D. Crispino, "Combinatorial regulation of tissue specification by GATA and FOG factors," Development, vol. 139, no. 21, pp. 3905-3916, 2012.

[63] F. Malek, J. Dvorak, J. Svitil et al., "Correlation of lipoprotein(a) concentration with the extent of coronary artery disease in patients on lipid lowering therapy," Neuro Endocrinology Letters, vol. 2, pp. 55-59, 2012.

[64] M. Greif, T. Arnoldt, F. von Ziegler et al., "Lipoprotein(a) is independently correlated with coronary artery calcification," European Journal of Internal Medicine, vol. 24, no. 1, pp. 75-79, 2013.

[65] Z.-G. Li, G. Li, Y.-L. Zhou et al., "Lack of association between lipoprotein(a) genetic variants and subsequent cardiovascular events in Chinese Han patients with coronary artery disease after percutaneous coronary intervention," Lipids in Health and Disease, vol. 12, article 127, 2013.

[66] H. Konishi, K. Miyauchi, T. Kasai et al., "Impact of lipoprotein(a) as residual risk on long-term outcomes in patients after percutaneous coronary intervention," American Journal of Cardiology, vol. 115, no. 2, pp. 157-160, 2015. 
[67] V. Gudnason, "Lipoprotein (a): a causal independent risk factor for coronary heart disease?" Current Opinion in Cardiology, vol. 24, no. 5, pp. 490-495, 2009.

[68] A. von Zychlinski, T. Kleffmann, M. J. A. Williams, and S. P. McCormick, "Proteomics of Lipoprotein(a) identifies a protein complement associated with response to wounding," Journal of Proteomics, vol. 74, no. 12, pp. 2881-2891, 2011. 


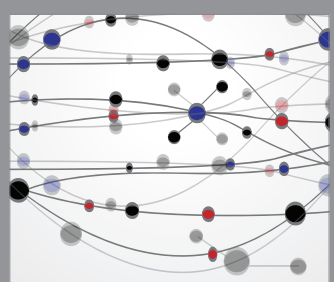

The Scientific World Journal
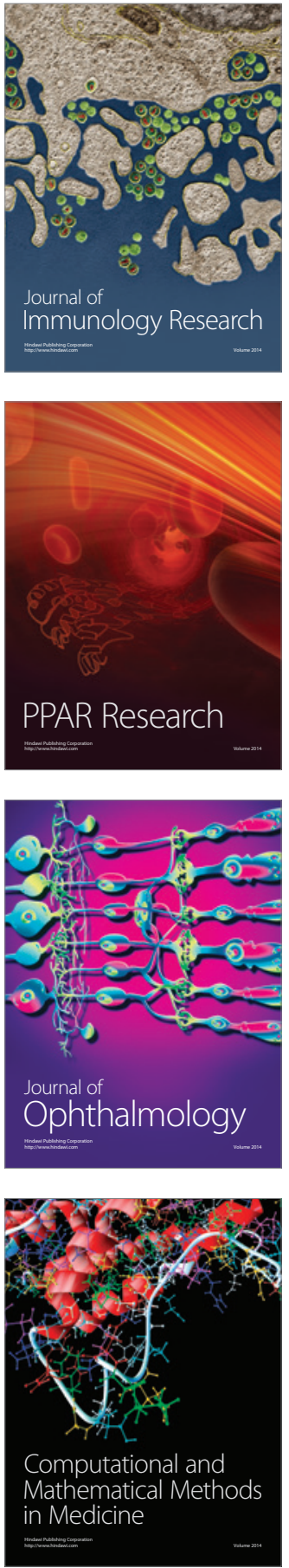

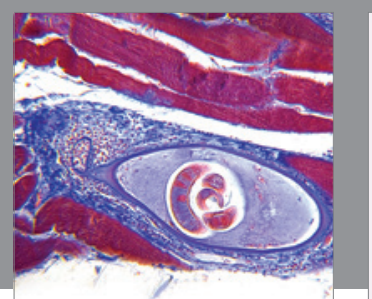

Gastroenterology Research and Practice

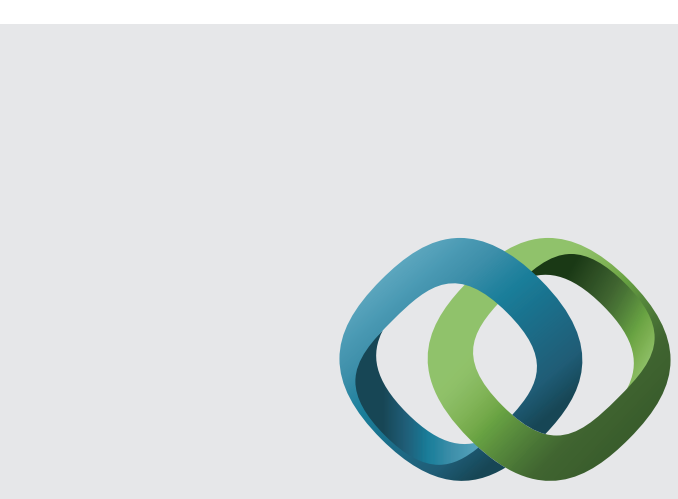

\section{Hindawi}

Submit your manuscripts at

http://www.hindawi.com
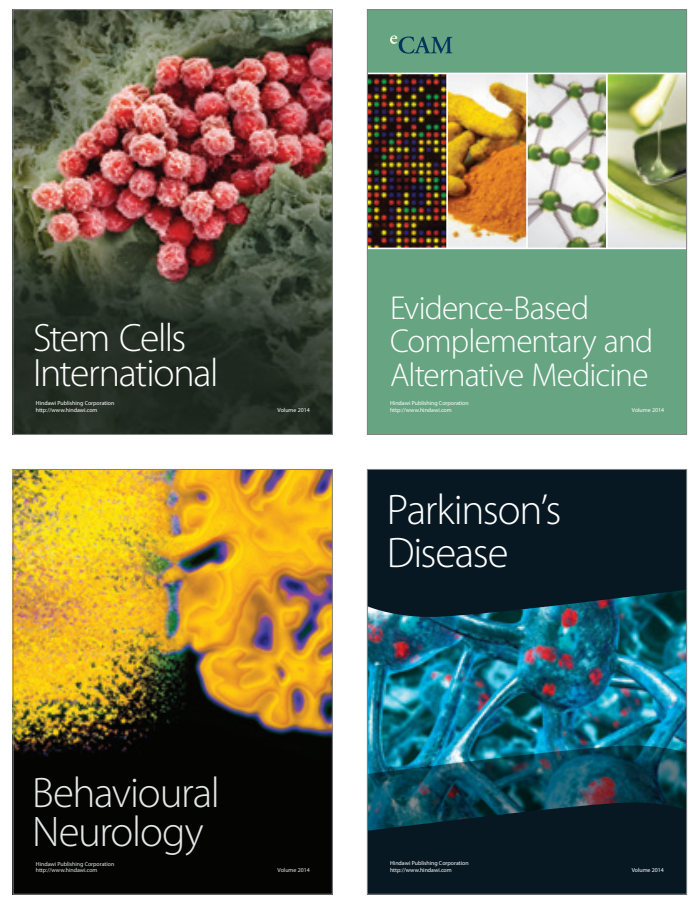
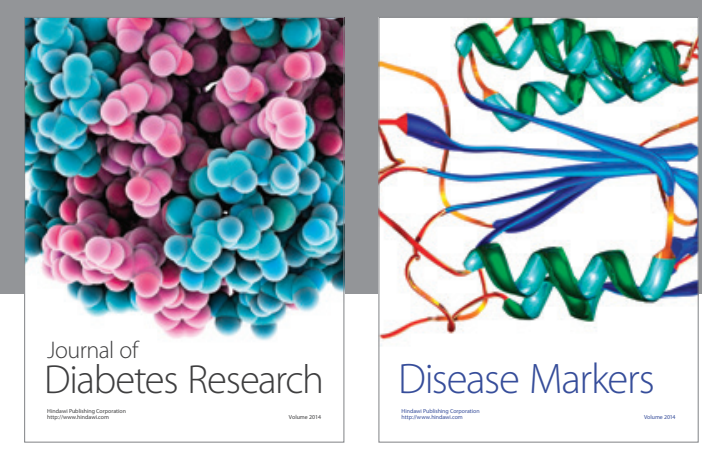

Disease Markers
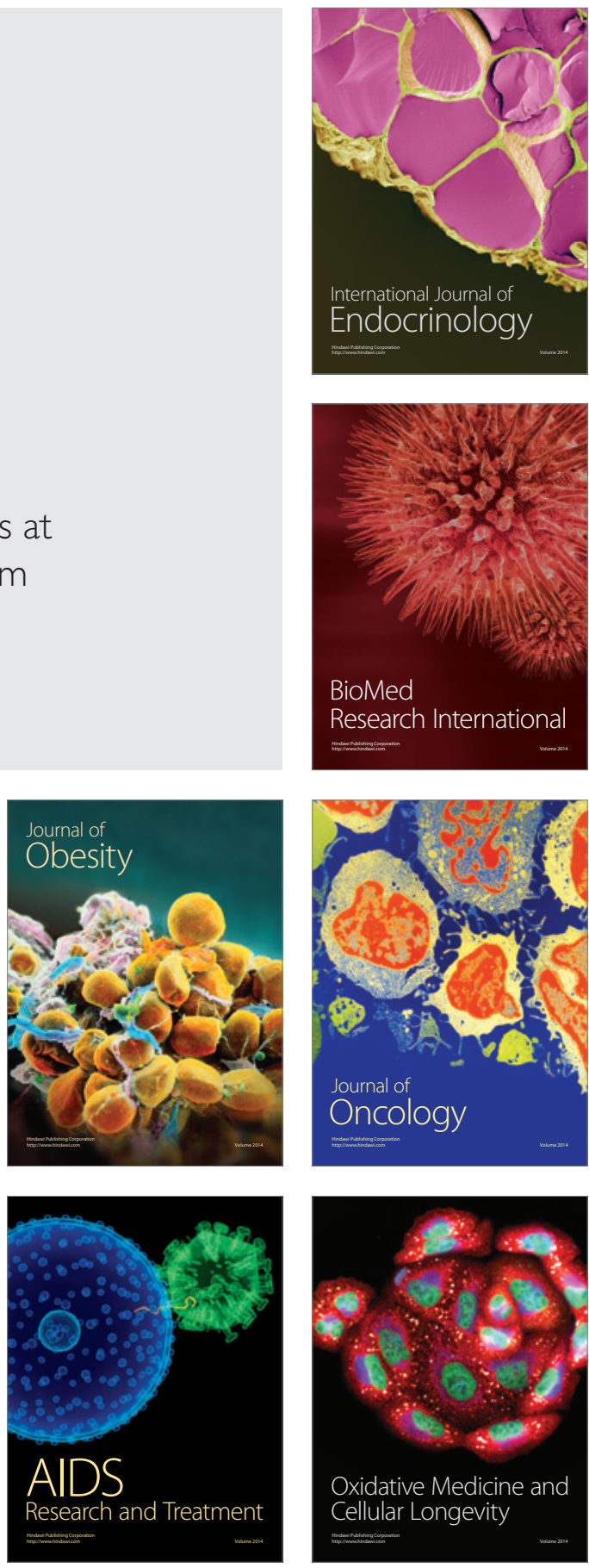